\title{
Transgender and Gender Nonconforming Youths' Public Facilities Use and Psychological Well-Being: A Mixed-Method Study
}

Lance S. Weinhardt, ${ }^{1, *}$ Patricia Stevens, ${ }^{2}$ Hui Xie, ${ }^{1}$ Linda M. Wesp, ${ }^{2}$ Steven A. John, ${ }^{1,3}$

Immaculate Apchemengich, ${ }^{1}$ David Kioko, ${ }^{1}$ Shannon Chavez-Korell, ${ }^{4}$ Katherine M. Cochran, ${ }^{4}$

Jennifer M. Watjen, ${ }^{4}$ and Nickolas H. Lambrou ${ }^{4}$

\begin{abstract}
Purpose: In this study, we explored experiences and feelings of safety in public facilities in relation to psychological well-being among transgender and gender nonconforming (TGNC) youth in the Midwest in the summer of 2016, in the context of ongoing legislative proposals and regulations regarding school and public bathroom use in the United States.

Methods: We used a mixed-method approach, with (1) a self-administered, paper-and-pencil survey of 120 TGNC youth, focusing on differences of self-esteem, resilience, quality of life (QoL), perceived stigma, feelings of safety, and experiences of public facility use and (2) two focus group interviews $(n=9)$ in which TGNC youth discussed individual perceptions, attitudes, and experiences of bathroom use outside participants' homes. The samples consisted predominantly of individuals assigned female at birth and currently of trans-masculine identity.

Results: TGNC youth in our sample who reported that they had felt unsafe in bathrooms due to appearance or gen-

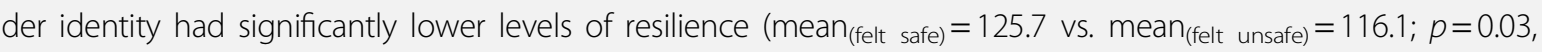
Cohen's $d=0.44$ ) and QoL (mean (felt safe) $=59.1$ vs. mean $_{\text {(felt unsafe) }}=51.9 ; p=0.04$, Cohen's $d=0.39$ ), compared to those who felt safe. Meanwhile, feeling unsafe in bathrooms was associated with a greater level of perceived LGBT stigma (mean (felt safe) $=2.3$ vs. mean $_{\text {(felt unsafe) }}=2.6 ; p=0.03$, Cohen's $d=0.41$ ) and problematic anxiety in the past year $\left(\chi^{2}(1)=4.06 ; p=0.04\right)$. Individuals in the focus groups provided specific examples of their experiences of and concerns about locker room or bathroom use in public facilities, and on the impact of school bathroomrelated policies and legislation on them.

Conclusion: Perceptions of safety related to bathroom use are related to psychological well-being among TGNC youth. Our predominantly trans-masculine youth sample indicated that choice of bathroom and locker room use is important and that antiharassment policies need to support students' use of their choice of bathrooms. This is particularly important information given debate of so-called bathroom bills, which attempt to restrict public bathroom use for TGNC youth, creating less choice and more stress and fear among these individuals.
\end{abstract}

Keywords: anti-transgender legislation; bathroom use; gender-expansive; gender minority youth; health disparities; transgender

\footnotetext{
'Joseph J. Zilber School of Public Health, University of Wisconsin-Milwaukee, Milwaukee, Wisconsin.

${ }^{2}$ College of Nursing, University of Wisconsin-Milwaukee, Milwaukee, Wisconsin.

${ }^{3}$ Center for HIV/AIDS Educational Studies and Training, Hunter College of the City University of New York, New York, New York.

${ }^{4}$ Department of Educational Psychology, School of Education, University of Wisconsin-Milwaukee, Milwaukee, Wisconsin.

*Address correspondence to: Lance S. Weinhardt, PhD, Joseph J. Zilber School of Public Health, University of Wisconsin-Milwaukee, P.O. Box 413, Milwaukee, WI 53201-0413, E-mail: weinhard@uwm.edu
}

(C) Lance S. Weinhardt et al. 2017; Published by Mary Ann Liebert, Inc. This is an Open Access article distributed under the terms of the Creative Commons Attribution License, which permits unrestricted use, distribution, and reproduction in any medium, provided the original work is properly cited. 


\section{Introduction}

The United States is experiencing widespread political debate on transgender $r^{\dagger}$ and gender nonconforming (TGNC) youths' use of public facilities, such as bathrooms and locker rooms, in accordance with their gender identity. In May 2016, after several court cases had developed and several states had attempted to create laws restricting transgender student's bathroom use, agencies of the Obama Administration issued a directive instructing public schools across the country to allow transgender students to use the bathroom that matches their gender identity. ${ }^{1,2}$ Jointly, the U.S. Department of Education (DOE) and the U.S. Department of Justice (DOJ) clarified that the civil rights of transgender school students are protected under Title IX (of the Education Amendments of 1972), which prohibits sex discrimination. In the weeks that followed, 11 states sued the federal government over the directive. ${ }^{3}$ Meanwhile, North Carolina had passed into law House Bill 2, which required all people to use public bathrooms in accordance with their sex assigned at birth, regardless of their gender identity or physical presentation ${ }^{4}$ and the DOJ sued that state to overturn the law. Many other states have proposed legislation and continue to hold public debates on the issue. In January 2017, the Trump Administration's DOJ and DOE rescinded the previous guidance on and federal support for transgender students, indicating they would not pursue federal enforcement of title IX violations. As these political debates continue and laws are proposed, it is crucial to understand the impact on the health and well-being of transgender youth, who must navigate the impact of these policies in the context of well-documented and widespread victimization from peers and others in their daily lives due to their gender identity and expression. ${ }^{5}$

Proponents of laws and policies restricting public facility use to correspond with sex assigned at birth claim to protect individuals from violence or indiscretion by perpetrators if transgender people are allowed to use facilities according to their gender identity. Yet, major national antiviolence organizations have disputed these scenarios as a myth, and suggest that forcing transgender people into facilities that do not align with their gender places them at increased risk for experiencing harm. ${ }^{6}$

Data collected from adults indicate that the majority of transgender people are fearful of using public facili-

\footnotetext{
${ }^{\dagger}$ The term transgender will be used interchangeably throughout this article with the term gender minority to describe individuals who have a gender identity that is different from the sex assigned at birth. We intend for these terms to encompass a wide spectrum of diverse identities that may or may not fall within traditional binary categories of male or female genders.
}

ties, according to the 2015 National Transgender Survey of more than 28,000 transgender people age 18 years and older, collected in 2015 before the introduction of most bathroom bills. ${ }^{7}$ In this survey, $59 \%$ of respondents reported avoiding using public restroom facilities in the past year because they were afraid of confrontations, with $12 \%$ experiencing verbal harassment and $1 \%$ reporting being the victim of physical or sexual assault in a public restroom. ${ }^{7}$ In one of the few studies with youth, the 2015 National School Climate Survey found that 39\% of students said they avoided gender segregated spaces because they felt uncomfortable or unsafe due to their gender presentation, and $60 \%$ of transgender students reported they were forced to use a facility that matched their sex assigned at birth instead of one that aligned with their gender identity. ${ }^{5}$ There are scarce data from the perspective of school-age transgender youth for whom public facilities use policies and debate may have a daily effect.

In general, the relationship between marginalization and mental health sequelae in gender minority populations is well documented. In one community-based sample of transgender people age $18-72$ years $(n=412)$, $44 \%$ reported clinically significant symptoms of posttraumatic stress disorder (PTSD), which were both independently and significantly associated with higher everyday discrimination scores as well as greater number of reasons for discrimination. ${ }^{8}$ Another study of 216 transgender young women aged 16-24 years found that youth who reported higher exposure to transgenderbased discrimination had almost three times the odds of PTSD compared to those with lower exposure and eight times higher odds of stress related to thoughts of suicide. ${ }^{9}$ Earlier studies have documented mental health outcomes of experiences in public facilities among transgender adults, with individuals who have been denied access to a public facility being 1.45 times as likely to have attempted suicide than those who had not been denied. Seelman found that denial of access to bathrooms or gender appropriate housing was significantly related to suicidality. ${ }^{10}$

The gender minority stress model provides an important perspective for the relationship between experiences of discrimination and mental health disparities among transgender individuals. ${ }^{11,12}$ The model suggests that proximal and distal stressors resulting from experiences of discrimination and victimization have a direct and negative impact on psychological health outcomes, whereas resilience factors can act as mediators to improve psychological well-being in the face of minority stress. For example, previous mixed-methods research 
with adults navigating gendered public facilities did not measure mental health outcomes, but found that proximal and distal minority stressors impacted functioning at work or school and participants described the negative psychological impact of stigmatization and consistent challenges to their identity. ${ }^{13}$ Given that transgender youth are now at the center of a highly public debate regarding their identity and how it relates to their access to public facilities, a space where transgender youth are already reporting high rates of discrimination and bullying, ${ }^{5}$ research with transgender youth to explore stress and resilience in relationship to public facilities is timely and important.

In this mixed methods study, we surveyed TGNC youth to examine how school bathroom experiences might be associated with psychological well-being. We also recruited TGNC youth to participate in focus groups to learn about their reactions to the bathroom debates described above and understand in more detail their experiences related to bathroom and locker room use in school. We collected both sets of data in an urban area of a Midwestern state during June 2016. The timing of the study allowed us to assess individuals targeted by legal and policy conflicts about gender identity and sex assigned at birth as these events were unfolding. The survey component of the study is presented first, followed by the focus group component. Discussion of both aspects of the study concludes the article.

\section{Study 1: Quantitative Survey}

Based on the gender minority stress model, we hypothesized that TGNC youth who felt unsafe or experienced problems in bathrooms due to appearance and gender identity would have significantly adverse psychosocial and health outcomes compared to those who did not.

\section{Participants}

The Gender Identity and Health Youth Survey was conducted over several days of a LGBTQ Pride Event held in a Midwest urban center. A convenience sample of 127 youth, aged between 13 and 20 years (mean $=17.2$, standard deviation $[\mathrm{SD}]=1.8$ ) participated.

\section{Procedures}

Graduate students conducted surveys at the booth of a national transgender support and education organization. Every attendee who passed by the booth who appeared to be under 21 was invited to complete a 6-item screening form for eligibility. This approach was used to maximize representation and minimize researcher bias, as well as to protect participants from revealing their gender identities in public. As opposed to the focus groups, parental consent was waived for the surveys due to the following reasons: the survey was anonymous and posed minimal risk to participants, disclosure of transgender identity to parents who were not aware could put some participants at risk for confrontational responses, and parental consent was not feasible due to the venue of data collectionmost youth attended the festival without parents. All participants were aware that all responses were voluntary, and that the data were to be used for research purposes.

Of the individuals approached for the study, 406 agreed to be screened and 127 (31\%) met the inclusion criteria and completed the survey. The survey was an anonymous, paper-and-pencil, and self-administrated questionnaire. The survey took an average of $20 \mathrm{~min}$ to complete (range: $15-30 \mathrm{~min}$ ). Participants received a gift worth $\$ 5$ for their participation. The research protocol was approved by the University of WisconsinMilwaukee's Institutional Review Board.

\section{Measures}

Demographic characteristics. Participants were asked about their race/ethnicity, age, living environment/situation, sex assigned at birth, gender identity, sexual orientation, and gender and sexual alliance (GSA) involvement. Two questions about gender identity were asked, both with multiple options and open-ended context where respondents could provide the best fitting response. The first question was "what is your current gender identity"; the responses included: (1) man/boy, (2) women/girl, (3) genderqueer, neither exclusively male nor female, and (4) additional gender. To further articulate individual gender identity and whether it corresponds to their assigned sex at birth, another selfidentification question was prompted to exclusively capture their transition status or non-cisgender identity (e.g., agender, transgender male, transgender female, gender nonconforming, genderqueer, non-binary, and other) at their unique identity development stage. There were two questions of GSA involvement that asked participants to check "yes" if involved in a school GSA and defined their role. Three single dichotomous items were asked for self-reported depression, anxiety, and medical problems in the past 12 months. An example of the items was "Have you experienced anxiety that caused problems for you in the past year?"

Self-esteem. Self-esteem was assessed by the 10-item Rosenberg Self-Esteem Scale (RSES), ${ }^{14}$ a widely used 
measure. Participants responded to questions on a 4-point Likert scale ranging from 1 (strongly agree) to 4 (strongly disagree). An example item was "On the whole, I am satisfied with myself." Responses were summed, yielding an overall score ranging from 10 to 40 . The greater the score, the more self-esteem reported by the participants. The reliability and validity of the instrument has been found to be acceptable in adolescents (Cronbach's $\alpha$ range: $0.89-0.95) .{ }^{15,16}$

LGBT stigma (stigma). We adapted Logie and Earnshaw's sexual stigma scale to measure frequencies of experienced discrimination, including stereotype, enacted stigma, and harassment. ${ }^{17}$ We added two items related to stigma or discrimination experiences in school and public bathrooms, and removed two items that were not relevant for youth. This 12-item scale uses a 4-point scale ranging from 1 (Many times) to 4 (Never). After conducting an exploratory factor analysis using principal components analysis with varimax rotation, 12 items loaded on two factors, consistent with the analysis of the original scale: perceived stigma and enacted stigma. ${ }^{17}$ Perceived Stigma (six items) reflected experiences of perceived or felt-normative stigma (i.e., hearing or feeling social devaluation of queer, lesbian, and bisexual women), which included such statements as "How often have you heard that LGBT+ people are 'not normal." Another factor, named Enacted Stigma (six items), referred to the tangible behaviors and interactions of discrimination, hate, prejudice, or stigma from others; one such item is "How often have you been harassed by teachers, school staff, or police for being LGBT +." All items were reverse scored so that higher scores indicated greater perceived stigma. The internal reliability for this overall scale was 0.88 (Perceived Stigma Subscale: Cronbach's $\alpha=0.84$; Enacted Stigma Subscale: Cronbach's $\alpha=0.84$ ).

Resilience. The Resilience Scale (RS) is a 25-item selfreport questionnaire using a 7-point Likert scale from 1 (strongly disagree) to 7 (strongly agree). ${ }^{18}$ An example question is "When I make plans I follow through with them." The RS is well-adapted to evaluate resilience in adolescents due to good psychometric properties (Cronbach's $\alpha$ range: $0.91-0.93$ ) and applications in a variety of age groups. ${ }^{19-21}$

Quality of life. We used the youth quality of life (YQoL) scale. ${ }^{22,23}$ The scale includes four domains of quality of life (QoL): sense of self, social relationships, culture and community environment, and general QoL. ${ }^{23-25}$
Responses are rated on an 11-point Likert-type scale, ranging from 0 (Not at all) to 10 (Very much). A sample item is "I am able to do most things as well as I want." The YQoL-SF 2.0 scale has acceptable internal consistency (Cronbach's $\alpha$ range: $0.77-0.96){ }^{23}$

Policy and environment. Two dichotomous questions assessed participants' awareness of the U.S. policies regarding public facility usage, including local state bills and the joint announcement from the DOJ and $\mathrm{DOE}$ (yes/no). Also, three items were used to measure safety and bathroom use in public; a sample question asked "Have you felt unsafe in bathrooms due to your appearance or gender identity." In addition, we assessed current public facility use with a single item: "Which bathrooms do you typically use when outside the home" with possible responses: "I use bathrooms according to my gender identity," "I use bathrooms consistent with my gender assigned at birth," "I only use unisex/family bathrooms," and "It depends on the situation and setting."

\section{Data analyses}

Before conducting data analyses, we excluded seven participants who reported being cisgender or did not provide current gender identities in the survey, leaving a final sample of $n=120$. We examined missing data patterns and mean-imputed variables with $7.5 \%$ of values missing at random. $t$-Tests were used to determine differences in self-esteem, resilience, perceived stigma, and YQoL by feelings of using bathrooms in school (safe vs. unsafe). Another set of one-way analysis of variance tests was conducted to determine differences in self-esteem, resilience, perceived stigma, YQoL by individual discriminatory experiences of using bathrooms in school. Chi-square analyses were used to assess differences in anxiety, depression, and medical problems by descriptive characteristics (feeling safety and experience problems in bathrooms). In addition, we explored the relationship between social support and feelings and experiences of using bathrooms in school. Analyses were conducted using SAS 9.4 for Windows.

\section{Quantitative results}

Demographic and descriptive characteristics. See complete demographics in Table 1 . The majority of participants were assigned female sex at birth $(n=107,89 \%)$. Regarding current gender identity, 40 currently identified as man/boy (32\%), and 51 were genderqueer (40\%). When given an open choice on gender identity, $32 \%$ identified as gender queer/non-binary, $29 \%$ 
Table 1. Demographics and Descriptive Statistics in the Gender Identity and Health Youth Survey $(n=120)$

Variable Mean (SD) $\quad n$ (\%)

\begin{tabular}{lc}
\hline Age (years) & $17.2(1.8)$ \\
Race/ethnicity & \\
White & \\
Hispanic/Latino & $11(70.6)$ \\
Black & $11(9.2)$ \\
Native American/American Indian & $2(1.7)$ \\
Other & $4(3.4)$ \\
Type of living environment & $18(15.1)$ \\
Urban & \\
Suburban & $37(31.1)$ \\
Rural area & $63(52.9)$ \\
Other & $10(8.4)$ \\
Assigned sex at birth & $9(7.6)$ \\
Male & \\
Female & $13(10.8)$ \\
\end{tabular}

Gender identity $1^{\text {a }}$

Man/boy

Women/girl

Genderqueer/non-binary

Other

Gender identity $2^{\mathrm{b}}$

Agender

Transgender

Gender nonconforming

Genderqueer

Non-binary

Other

Multiple

Sexual orientation

Lesbian, gay, or homosexual 23 (19.2)

Straight or heterosexual

Bisexual or pansexual

Questioning

Other or multiple

$37(31.1)$

$15(12.6)$

$51(42.9)$

$16(13.4)$

$7(5.9)$

$34(28.6)$

$6(5.0)$

$22(18.5)$

$16(13.4)$

$15(12.6)$

$19(16.0)$

$9(7.5)$

$57(47.5)$

$6(5.0)$

$22(18.3)$

School access to bathrooms consistent with gender identity ${ }^{c}$ Yes

No

Don't know

Don't go to school currently

Wisconsin legislature ${ }^{\mathrm{d}}$

Yes

No

Joint announcement ${ }^{\mathrm{e}}$

Yes

No

Negative bathroom experience ${ }^{f}$

Yes

No

Felt unsafe ${ }^{9}$

Yes

No

Bathroom use ${ }^{\mathrm{h}}$

Gender identity

Assigned sex at birth

Unisex/family bathrooms

Situational choices

37 (30.8)

$25(20.8)$

$35(29.2)$

$23(19.2)$

$74(63.8)$

$42(36.2)$

$72(61.5)$

$45(38.5)$

$54(45.8)$

$64(54.2)$

$66(56.4)$

$51(43.6)$

19 (16.2)

$40(34.2)$

$12(10.3)$

$46(39.3)$

Problematic depression in past year

Yes

No $104(87.4)$ $15(12.6)$
Table 1. (Continued)

\begin{tabular}{|c|c|c|}
\hline Variable & Mean (SD) & $n(\%)$ \\
\hline \multicolumn{3}{|c|}{ Problematic anxiety in past year } \\
\hline Yes & & $113(95.0$ \\
\hline No & & $6(5.0)$ \\
\hline \multicolumn{3}{|c|}{ Medical problems in past year } \\
\hline Yes & & $47(39.8$ \\
\hline No & & $71(60.2$ \\
\hline
\end{tabular}

${ }^{\mathrm{a}}$ Gender identity 1 denotes self-identified gender identity.

${ }^{b}$ Gender identity 2 denotes self-identified non-cisgender identity.

'School access denotes whether school allows them to use the bathroom consistent with their gender identity.

${ }^{d}$ Wisconsin legislature denotes a bill proposal last year trying to limit transgender people's bathroom use to their sexual assigned at birth in Wisconsin.

e Joint announcement denotes the U.S. Department of Justice and Department of Education released policies that instruct schools and colleges to treat transgender students according to their gender identity on bathroom and locker room use.

fBathroom experience denotes discriminatory experiences of using bathrooms related to their appearance or gender identity in public.

${ }^{9}$ Felt unsafe denotes whether they have felt unsafe in bathrooms due to their appearance or gender identity in public.

hathroom use denotes bathrooms they usually use in public.

$\mathrm{SD}$, standard deviation.

transgender, $6 \%$ as agender, $5 \%$ gender expansive, and $29 \%$ another gender identity. About $69 \%$ of participants were non-Hispanic white, $10 \%$ identified as Hispanic or Latino, $14 \%$ were multiracial identities.

About $64 \%$ of participants were aware of local state legislation proposals regarding transgender people's bathroom access. Also, $62 \%$ were aware of the joint announcement from the DOJ and DOE.

Regarding public facility experiences, $46 \%$ reported having experienced problems using public bathrooms $(n=54)$. In addition, 56\% $(n=66)$ felt unsafe using public bathrooms. Thirty-four percent of participants $(n=40)$ said they used the bathrooms consistent with their sex assigned at birth while $16 \%(n=19)$ went to public bathrooms corresponding to their current gender identity. Another 39\% $(n=46)$ reported it depended on the situation, and $10.3 \%(n=12)$ only used unisex/family bathrooms.

In this sample of 120 predominantly transmasculine TGNC youth, the mean score for the RSES was 24.9 (range: $10-39, \mathrm{SD}=6.4$ ). Scores below 25 indicate low-esteem and scores of 25-35 are considered typical self-esteem. ${ }^{14}$ In our sample $44 \%$ of participants had low-self-esteem (overall RSES score <25).

The mean score for the RS was 120.3 (range: 53-169,
$\mathrm{SD}=23.1$ ). After repeated applications of the RS with a variety of samples, Wagnild concluded that scores greater than 145 indicated moderately high-to-high resilience, 
Table 2. Psychological Scales in Gender Identity and Health Youth Survey $(n=120)$

\begin{tabular}{lcrr}
\hline Scale & Range & Mean & SD \\
\hline RSES $^{\text {a }}$ & $10-39$ & 24.9 & 6.4 \\
LGBT stigma $^{\text {b }}$ & $1-4$ & 2.5 & 0.7 \\
Perceived stigma $_{\text {Enacted stigma }}$ & $1-4$ & 2.9 & 0.7 \\
Resilience $^{c}$ & $1-4$ & 2.1 & 0.8 \\
YQoL $^{d}$ & $53-169$ & 120.3 & 23.1 \\
\end{tabular}

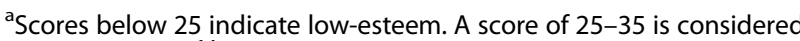
typical self-esteem. ${ }^{14}$ In our sample $44.4 \%$ of participants had low-selfesteem (overall RSES score $<25$ ).

${ }^{b}$ We adapted the sexual stigma scale, which was designed for LGB adult women. The authors provide their original sample means for the total scale as $2.0(\mathrm{SD}=0.45) .{ }^{17}$ They also provide means for the Perceived Stigma subscale as $2.67(\mathrm{SD}=0.70)$ and for the Enacted Stigma subscale as $1.51(\mathrm{SD}=0.40)^{17}$

'Wagnild reviewed three adolescent health studies that used the RS. ${ }^{21}$ Among these three studies, the overall mean scores were 146.6 $(\mathrm{SD}=14.1)$ in adolescent mothers, $111.9(\mathrm{SD}=17.6)$ in homeless adolescents, and 132.5 in high-risk adolescents. ${ }^{21}$ Possible scores range from 25 to 175 . After repeated applications of the RS with a variety of samples, scores greater than 145 indicated moderately high-to-high resilience, 125-145 indicated moderately low to moderate levels of resilience, and scores of 120 and below indicated low resilience. ${ }^{21}$

${ }^{d}$ Patrick et al. used a 6-item version of this scale in a large sample of high-school age LGB youth. ${ }^{25}$ They reported scores across different categories of participants (by grade, by gender, and by whether or not they were bullied due to perceived sexual orientation or other factors). QoL scores ranged from 54 to 83 across these different combinations of categories. The observed score here is at the lower end of the range of scores reported in Patrick, consistent with LGB students who had been bullied because of perceived sexual orientation. ${ }^{25}$ Scores are comparable between studies because the total scale score on the YQoL is the total of transformed item scores divided by the number of items.

QoL, quality of life; RSES, Rosenberg Self Esteem Scale; YQoL, youth QoL.

125-145 indicated moderately low to moderate levels of resilience, and scores of 120 and below indicated low resilience. $^{21}$ In our sample, $13 \%(n=16)$ reported moderately high-to-high resilience, $41 \%(n=49)$ reported moderate to moderately low resilience, and $46 \%(n=55)$ reported low resilience.

The mean score for the LGBT Stigma scale was 2.5 (range: $1-4, \mathrm{SD}=0.71$ ). The mean score for the YQoL was 55.0 (range: $14-100, \mathrm{SD}=18.3$ ). See psychological scales and additional normative/comparison data in Table 2 .

Feelings of safety in bathrooms in relation to psychological and physical well-being. TGNC youth who reported that they had felt unsafe in bathrooms due to appearance or gender identity had significantly lower levels of resilience $\left(\operatorname{mean}_{\text {(felt safe) }}=125.7\right.$ vs. $\operatorname{mean}_{\text {(felt unsafe) }}=116.1$; $p=0.03$, Cohen's $d=0.44)$ and QoL $\left(\operatorname{mean}_{\text {(felt safe) }}=59.1\right.$ vs. $\operatorname{mean}_{\text {(felt unsafe) }}=51.9 ; p=0.04$, Cohen's $d=0.39$ ), compared to those who felt safe. Meanwhile, feeling unsafe in bathrooms was associated with a greater level of perceived LGBT stigma ( mean $_{\text {(felt safe) }}=2.3$ vs. $\operatorname{mean}_{\text {(felt unsafe) }}=2.6$;
Table 3. Comparison on Psychological Variables and Well-Being Among Transgender and Gender Nonconforming Youth Based on Feeling Unsafe in Bathrooms $(n=117)$

\begin{tabular}{lccc}
\hline & $\begin{array}{c}\text { Felt safe } \\
\text { in bathrooms, } \\
\text { mean (SD), } \\
\text { or } \boldsymbol{n}(\%)\end{array}$ & $\begin{array}{c}\text { Felt unsafe } \\
\text { in bathrooms, } \\
\text { mean (SD), } \\
\text { or } \boldsymbol{n}(\%)\end{array}$ & t-test/ $\chi^{2}(1)$ \\
\hline Self-esteem $^{\mathrm{a}}$ & $26.22(6.71)$ & $23.98(6.08)$ & -1.88 \\
Resilience $^{\mathrm{a}}$ & $125.67(24.31)$ & $116.06(21.86)$ & $-2.25^{*}$ \\
QoL $^{\mathrm{a}}$ & $59.09(20.29)$ & $51.89(16.17)$ & $-2.14^{*}$ \\
LGBT stigma $^{\text {a }}$ & $2.34(0.77)$ & $2.64(0.63)$ & $2.23^{*}$ \\
Anxiety in past year $^{\text {b }}$ & $46(90.2)$ & $65(98.5)$ & $4.06^{*}$ \\
Depression in past year $^{\mathrm{b}}$ & $43(84.3)$ & $59(89.4)$ & 0.66 \\
Medical problems $^{\mathrm{b}}$ & $16(31.4)$ & $30(46.2)$ & 2.61
\end{tabular}

${ }^{*} p<0.05$.

${ }^{a} A$ composite score.

${ }^{\mathrm{b}} \mathrm{A}$ dichotomous variable.

$p=0.03$, Cohen's $d=0.41$ ). Individuals who felt unsafe were also more likely to report problematic anxiety in the past year $\left(\chi^{2}(1)=4.06 ; p=0.04\right.$; Table 3$)$.

Problems experienced in bathrooms in relation to psychological and physical well-being. As shown in Table 4, participants who reported experiencing problems using bathrooms due to appearance or gender identity reported higher levels of perceived LGBT stigma compared to those who reported no problems $\left(\operatorname{mean}_{(\text {experienced no problems) }}=2.3\right.$ vs. mean $_{\text {(experienced problems) }}=2.8 ; p<0.001$, Cohen's $d=0.80)$. There were no significant differences on self-esteem, resilience, and QoL between those who had experienced problems and those who had not.

To complement the quantitative data and to examine in more depth the relationships between perceptions and experiences of bathroom use, legislation,

Table 4. Comparison on Psychological Variables and Well-Being Among Transgender and Gender Nonconforming Youth Based on Experiencing Problems in Bathrooms Due to Gender Identity or Expression $(n=118)$

\begin{tabular}{lccc}
\hline & $\begin{array}{c}\text { Did not experience } \\
\text { problems } \\
\text { in bathroom, } \\
\text { mean (SD), } \\
\text { or } \boldsymbol{n}(\%)\end{array}$ & $\begin{array}{c}\text { Did experience } \\
\text { problems } \\
\text { in bathroom, } \\
\text { mean (SD), }\end{array}$ & $\begin{array}{c}\text { or } \boldsymbol{n}(\%) \\
\chi^{2}(1)\end{array}$ \\
\hline Self-esteem $^{\mathrm{a}}$ & $25.19(6.39)$ & $24.65(6.46)$ & -0.45 \\
Resilience $^{\mathrm{a}}$ & $121.00(25.02)$ & $119.44(21.17)$ & -0.36 \\
QoL $^{\mathrm{a}}$ & $55.40(18.74)$ & $55.02(18.16)$ & -0.11 \\
LGBT stigma $^{\mathrm{a}}$ & $2.26(0.70)$ & $2.79(0.62)$ & $4.26^{* * *}$ \\
Anxiety in past year $^{\mathrm{b}}$ & $59(92.2)$ & $53(98.1)$ & 2.16 \\
Depression $^{\text {in past year }}$ & $57(89.1)$ & $46(85.2)$ & 0.40 \\
Medical problems $^{\mathrm{b}}$ & $21(32.8)$ & $25(47.2)$ & 2.51 \\
\hline
\end{tabular}

${ }^{* * *} p<0.001$.

${ }^{\mathrm{a}} \mathrm{A}$ composite score.

${ }^{\mathrm{b}} \mathrm{A}$ dichotomous variable. 
and mental health, and to better understand the lived experiences of TGNC youth in these areas, we conducted qualitative focus groups.

\section{Study 2: Qualitative focus groups}

Participants

Qualitative focus groups were organized with the assistance of the LGBT student resource center on the campus of a local university during outreach activities with LGBT high school students in the region. Before data collection, written informed assent was obtained from the teens and informed consent from their legal guardians. Potential participants of high school age who self-identified as transgender or had a gender identity other than the sex they were assigned at birth were invited to participate in a focus group. A total of nine people between the ages of 15 and 18 years and currently in high school participated in groups of four to five members. Six participants were nonHispanic white; three were ethnic/racial minorities (Black or Hispanic). All participants were assigned female sex at birth, with current gender identities self-described as transgender, genderqueer, or man/boy.

\section{Procedure}

The focus groups were facilitated by an experienced qualitative researcher and attended by a student member of the research team, and lasted about $2 \mathrm{~h}$. We began each focus group by bringing up the general topic of regulating bathroom use in schools, asking the teens for their reactions. Then, we invited them to share their own experiences around bathroom and locker room use in school. We continued with discussions about coming out as transgender, family support, and resilience. In this article, we present findings about bathroom and locker room use; findings about the other topics are presented elsewhere.

The focus groups were digitally recorded and transcribed. Using thematic analysis ${ }^{26,27}$ we examined how participants interpreted the public controversy about bathroom use, and how they described their experiences using bathroom and locker room facilities in school. Similarities in meaning and experience, as well as their variation, were iteratively identified and categorized, highlighting the social contexts youth described. ${ }^{28} \mathrm{We}$ concluded our analysis by finding exemplar quotes to substantiate the findings.

Qualitative results

Personal relevance of bathroom use policy. The TGNC teens who participated in the focus groups were keenly aware and critical of state legislatures trying to limit transgender people's bathroom use to their sex assigned at birth. They referred specifically to North Carolina, calling the state "dumb and mean" for passing the contentious House Bill 2 restricting transgender bathroom access. Participants found it hard to fathom why such a restriction would be mandated by law, and how it could be enforced:

When people won't let me use male bathrooms, it's like what are they going to do - look through the cracks in the bathroom stalls to see if I have the right genitalia?

They talked about how some people have religious objections to rights for the LGBTQ+ community, and they voiced compassion for those who, like some of their relatives, might need time to become informed about the issue. But, they were clear about the ethics of the situation:

Since gay marriage (being legalized) and all these new rights, everybody is just trying to take it down with bathroom bills. They believe they are right. But, in reality, if you use your faith or morals to hurt or exclude someone else, you have no morals or faith at all.

They brought up the topic of corporate backlash against North Carolina, which they considered a positive outcome of the controversy. They felt supported by news of prominent individuals and groups decrying restrictive bathroom bills:

You hear about Target that came out saying you can use the bathroom of your choice at our stores. Companies can help in a big way. We need people and corporations, big name companies, who will stand up for our rights.

A source of support identified by participants was the DOE's policy directive instructing schools to treat transgender students in a supportive and nondiscriminatory way. ${ }^{1}$ Participants were aware of the protections offered by the document, emphasizing the guideline that transgender students not be limited to bathrooms and locker rooms corresponding to their assigned sex at birth:

To hear that the government is saying- yes, what you are thinking is correct- it is fine that you use the bathroom of your choice. That is uplifting.

They were also aware of widespread objections to the Directive, however:

The President's letter is getting a lot of hate.

It is really scary that people are saying President Obama can't do this.

Of immediate importance to them was how their own high schools were responding to the Directive. For the 
most part, these teens were disappointed. What they perceived in the reactions of school officials was denial of the need for structural change to make schools inclusive of transgender teens, marginalization of transgender people, or complete disregard for the issue:

When President Obama sent the letter to let trans people use the bathroom of their choice, my school district sent out an email that said we're going to do it case-by-case. Caseby-case means we are not going to do it. It just sounds nice.

At my school they were very vague. They talked about us like these special people, making us sound like a very small group, like there's only one or two of us in the state. That makes me mad. And, they aren't presenting full information. Not a lot of people know about transgender stuff and understand, so they need education.

At my school there hasn't been any talk about it at all. No assemblies, no nothing by the principal or anything. They don't validate the issue.

Individual experiences related to bathroom policy. Bringing policy discussion down to the particular, participants were eager to explain what happens at their schools in regard to bathroom and locker room use.

Single-User Bathrooms: Accommodating or Discriminatory? Access to single-user bathrooms in school was important to participants; but according to the experiences they shared, it could be a doubleedged sword; offering privacy on the one hand, but singling them out on the other. One difficulty they encountered was being restricted from multiple-user bathrooms altogether. Another difficulty was that single-user bathrooms were locked or located in faculty/staff-only areas, potentially exposing students to unwanted attention from peers and adults and being seen as different from their peers:

I definitely have a problem at my school. I'm not allowed in any bathroom that is gendered. I have to ask for the key from a teacher in order to use the gender neutral bathroom. It is supposed to be for faculty only, so the door is locked.

At my school there is no gender neutral bathroom. But in the school office there is the only restroom that doesn't have a gender marker on it. It is not gender neutral- it just doesn't have a marker because it is for the teachers. They let me use it.

Participants talked about how access to single-user gender neutral bathrooms was helpful in negotiating clothes changes before and after gym class, but that this accommodation still had the potential to make them stand out from others. For instance, they might be the only person traversing a school hallway or entering a classroom in gym clothes:
I didn't feel comfortable in the female locker room. And, I wasn't allowed in the male locker room. I changed in the one gender neutral bathroom we have, but it was way on the other end of the school from the gym.

I didn't get a locker. I have legit valuables in my backpack just like everybody else, but I was supposed to put my stuff on a shelf in the health room. Sometimes there was a class in there and I had to walk in in front of everybody to put my stuff in there.

A private dressing room was not the only solution needed to make gym class comfortable for transgender students. For instance, one participant did not feel comfortable having to transit through gendered locker rooms just to attend:

The whole gym thing- our gym is like Fort Knox. No one's getting in and no one's getting out. I could change in an alternate place, but, the only entrance into the gym is through the gendered locker rooms. All the other doors are locked. I need to be able to get into the gym in a safe way.

Multiple-user bathrooms: What if they are hostile environments? Only a few participants reported they were allowed to use school bathrooms and locker rooms that corresponded to their gender identity. Although this was the preferred policy among participants, the practice did not resolve all problems for them. They recounted incidents of harassment and fear in multiple-user bathrooms consistent with their gender identity:

In the boys' bathroom at school, I guess you could say I have been harassed- called names.

My school said I could use the boys' locker room, like I could technically change with the boys. But, for safety reasons, until I'm on Testosterone, they put me in this official [referee's] room. It is still in the boys' locker room area, though.

Using multiple-user bathrooms corresponding to sex assigned at birth did not shield transgender teens from harassment, either:

I always hated long hair and dresses. I got my Mom to let me get all my hair cut off. After that I remember going into female restrooms and getting called a boy a lot, especially by the younger girls.

I've been kicked out of the female bathroom because I looked like a guy. This girl yelled at me for being a pervert because I was a guy in the girls' bathroom.

Further, transgender teens' inclinations about multipleuser bathrooms may be neither static nor easy. In determining whether they preferred to use a bathroom corresponding to their gender identity or to their sex assigned at birth, they might make calculations on any number of factors: how comfortable and self-assured they were feeling that day, whether the environment seemed safe, what their ideas about gender norms were, 
and how their appearance compared to peers. This quote conveys some of the complexity in their decision making:

I don't usually use the men's bathroom, even though I identify as gender queer. Personally, I wouldn't feel comfortable around guys, especially with how they would see me. I don't appear that masculine all the time, even though I don't identify as female. I feel like I don't need to appear as the gender norm. So, I might use the women's bathroom because it feels easier. But, I notice myself acting more feminine when I go in there just so I don't get looked at weird, especially if I am looking more masculine that day.

Stark contrast: Best and worst bathroom experiences in school. Developing a deeper understanding of the best and worst of any phenomenon can build knowledge and help guide practice. Such a contrast can be found in these focus group data. The most positively evaluated bathroom use experience shared in the focus groups happened in a school that publicly recognized gender identity as being more than the forced binary of male or female. With advice from its LGBTQ+ students, the school labeled its restrooms in a way that welcomed all students:

My school is really good about this. We have two gender neutral bathrooms that we officially got plaques for that say ALL GENDERS.

The most negatively evaluated bathroom use experience shared in the focus groups was offered by a maleidentified transgender participant who was habitually made to feel unsafe in his school's multiple-user bathrooms. He used the bathrooms corresponding to his gender identity:

My school lets me use the bathroom I want to use, which is the male bathroom. Students in my grade know me, and they say like, "You aren't supposed to be in here." They call me tranny or dyke or whatever. And, I just think, "Guess whatI could care less about your opinion. I'm going to piss now." I really don't care about verbal stuff. I just walk it off until it's nothing to me.

He deals with harassment in the bathroom, what he calls "verbal stuff," by privately undervaluing its significance and "walking it off." When threatened with violence in the male bathroom, he seems to again use self-talk to reassure himself:

I've been threatened a couple times in the male bathroom like, "Next time you come in here I'm going to kick you out." But I'm thinking, "How are you going to kick me out? You can't really hurt me. If you hurt me, my school will back me up."

He went on to sum up his school experience in disquieting terms:

Freshman year (of high school) wasn't extremely bad. I wasn't like bullied to death or anything- just a little bit here and there.

He explained further:
Nobody really wants to be my friend, but I could care less because I have always been an outcast to people. And with being alone, I kind of dealt with a lot of dysphoria. I had no one to talk to, so I was really quiet. And, I think that really impacted me.

In this transgender teen's narration, he indicated his bathroom experiences contributed to his feelings of being bullied and feeling isolated from others; and he uses the medical term "dysphoria" to describe his deep unhappiness.

\section{Discussion}

The current mixed method research contributes to the literature about TGNC youth in several important ways. First, both studies provided data from nonclinical samples of transgender youth. Quantitative survey results show that overall, the majority of this sample of predominantly transmasculine TGNC youth had felt unsafe using public bathrooms and almost half reported negative experiences using public bathrooms. Second, these data are from gender minority youth themselves, who are experiencing the effects of policies and practices in their daily lives, which has not been often represented in the literature. The quantitative data also provide evidence that gender minority youth who felt unsafe in bathrooms have adverse mental health impacts and lower QoL. The focus group interviews revealed narratives of negative experiences in locker rooms and bathrooms and discrimination, which has been impacted by ongoing transgender bathroom policies at federal and local levels.

Our qualitative findings suggest that transgender teens are aware of both the national debate on so-called bathroom bills, and the actions their own communities take to structure schools as inclusive or exclusive of transgender students. According to the experiences participants shared, bathroom and locker room use policy and practice affected their feelings of comfort, belonging, and safety in school. Our quantitative findings begin to document such associations. From the surveys we learned that more than half of gender minority youth feel unsafe using public bathroom facilities, and that these feelings of lack of safety are related to their own resilience, sense of perceived stigma, anxiety, and recent medical problems. Our findings are consistent with previous surveys regarding high rates of discrimination in public facilities. ${ }^{7,13}$ Our findings on resilience are consistent with previous findings among TGNC youth; experiencing invalidation of gender identity was related to lower levels of resilience. ${ }^{29}$

From the focus groups we learned that access to multiple-user bathrooms corresponding to gender identity is not a panacea for transgender students if not accompanied by policies and actions that support those who use them. Second, access to single-user bathrooms is 
important in conjunction with efforts to normalize their use for all students, so that transgender students are not singled out for discrimination. Third, transgender students want agency in their choices about bathroom use; what feels safe and appropriate on any given day in a particular social context at school may not feel safe and appropriate on another day given different circumstances. These findings suggest that navigating bathrooms and changing rooms at school, particularly when policies are not supportive or limit choice, are daily stressors for TGNC youth. According to the gender minority stress model, ${ }^{12}$ this can negatively impact mental health outcomes.

Based on the gender minority stress model, we hypothesized that TGNC youth who felt unsafe or experienced problems in bathrooms due to appearance and gender identity would have significantly adverse psychosocial and health outcomes compared to those who did not. In the quantitative survey, we found that TGNC youth who felt unsafe in bathrooms reported less psychological wellbeing across several measures, including self-esteem, resilience, QoL, and perception of stigma, and problematic levels of anxiety. Negative experiences in bathrooms were directly associated only with greater perception of stigma, while associations with other outcomes were not significant. This pattern of findings could be explained by the following: TGNC youth who feel unsafe in bathrooms due to their appearance or gender identity might avoid public bathroom situations to avoid dealing with discrimination.

Transgender people who avoid using public facilities out of fear may experience not only adverse psychosocial effects, such as lower QoL as we found in our study, but the resultant health consequences such as bladder or kidney infections resulting from avoiding public restroom use due to fear or inability to succeed academically due to avoiding days of school due to feeling unsafe or uncomfortable in bathrooms or locker rooms. ${ }^{5,7,30}$ Ongoing research building on our findings can further elaborate experiences and inform policy that will improve the QoL and health for TGNC youth.

\section{Study limitations and strengths}

The quantitative surveys were cross sectional and therefore cannot be used to determine the direction of causal relationships. The focus groups were a complementary approach to add depth and context to the quantitative findings. Both studies used convenience sampling, and the majority of the sample was non-minority, female-tomale transgender or transmasculine individuals; thus our findings might not be generalizable to other settings or segments of the TGNC population. The present research fo- cused on TGNC youth perspectives in the Midwest. Although this is not a nationally representative sample, we have no theory-based reason to expect relationships between feelings of safety and psychological and physical well-being to differ geographically. Our qualitative findings are limited by the fact that the focus groups were comprised exclusively of male- or non-binary-identified transgender teens whose sex assigned at birth was female, which does not allow us to draw conclusions about the experiences of female- or non-binary-identified transgender teens whose sex assigned at birth was male. Further research is clearly warranted to understand the experiences and impacts on the full range of TGNC youth, and to document the direction of causality between the observed associations. Despite these limitations, this study contributes unique and timely data and findings to the literature on this important public health issue.

\section{Conclusion}

This study provides initial evidence from a nonclinical setting addressing the potential impacts of current policies and so-called "bathroom bills" on distress and experiences of using public bathrooms among gender minority youth. The inclusion of voices of transgender youth themselves based on their direct experiences gives additional weight to these findings. Taken together, our qualitative and quantitative findings converge on a primary message and recommendations: transgender-related bathroom policies limiting use to sex assigned at birth or requiring use of only single-stall bathrooms will likely have a negative impact on health outcomes among TGNC youth. Policies that create more restrictive bathroom options for transgender students will likely create environments in which TGNC youth feel less safe in bathrooms and in school. Based on our data, this could lead to an increase in perceived stigma and discrimination, and less resilience, self-esteem, and lower QoL for these youth.

Feeling unsafe in public facilities may be an important contributing factor to perceived stigma and genderminority-related stress for TGNC youth, which may contribute to mental and physical health disparities in this population. Supportive school policies should allow bathroom choices for TGNC students. However, bathroom choice is not enough; policies and personnel must also clearly protect TGNC students from harassment. Promoting safety is paramount to improving the well-being of these students.

\section{Acknowledgments}

We thank Loree Cook-Daniels and michael munson of FORGE, Inc. of Milwaukee, WI, (forge-forward.org) 
for their support of the survey, Jen Murray, MPH, and the University of Wisconsin Milwaukee LGBT Resource Center for their assistance with the focus groups, and Nancy Muro for assistance with data entry. We also appreciate the input of Michael P. Carey, PhD, for comments on an earlier version of the manuscript. Finally, we are deeply grateful to all the participants who gave their time and insight to inform this research.

\section{Author Disclosure Statement}

No competing financial interests exist.

\section{References}

1. U.S. Department of Justice, Office of Public Affairs. U.S. Departments of Justice and Education release joint guidance to help schools ensure the civil rights of transgender students. The U.S. Department of Justice: Justice News. 2016. Available at: www.justice.gov/opa/pr/us-departments-justiceand-education-release-joint-guidance-help-schools-ensure-civil-rights (accessed November 4, 2016).

2. U.S. Department of Education, Office of Elementary and Secondary Education, Office of Safe and Healthy Students. Examples of policies and emerging practices for supporting transgender students. 2016. Available at: www .justice.gov/opa/file/850991/download (accessed November 5, 2016).

3. Richardson B. 11 states sue Obama administration over federal transgender school-bathroom directive. The Washington Times, May 25, 2016. Available at: www.washingtontimes.com/news/2016/may/25/11-states-sue-obamaadministration-over-guidance-t/ (accessed November 5, 2016).

4. Graham DA. North Carolina overturns LGBT-discrimination bans. The Atlantic, March 24, 2016. Available at: www.theatlantic.com/politics/ archive/2016/03/north-carolina-lgbt-discrimination-transgenderbathrooms/475125/ (accessed November 5, 2016).

5. Kosciw JG, Greytak EA, Giga NM, et al. The 2015 National School Climate Survey: The Experiences of Lesbian, Gay, Bisexual, Transgender, and Queer Youth in Our Nation's Schools. New York: Gay, Lesbian and Straight Education Network (GLSEN), 2016.

6. National Task Force to End Sexual and Domestic Violence Against Women. National consensus statement of anti-sexual assault and domestic violence organizations in support of full and equal access for the transgender community. April 7, 2016. Available at: http://endsexualviolence.org/files/NTF NationalConsensusStmtTransAccessFinal4-7.pdf (accessed November 5, 2016)

7. James SE, Herman JL, Rankin S, et al. The report of the 2015 U.S. transgender survey. Washington, DC: National Center for Transgender Equality, 2016.

8. Reisner SL, White Hughto JM, Gamarel KE, et al. Discriminatory experiences associated with posttraumatic stress disorder symptoms among transgender adults. J Couns Psychol. 2016;63:509-519.

9. Wilson EC, Chen $\mathrm{YH}$, Arayasirikul $\mathrm{S}$, et al. The impact of discrimination on the mental health of Trans*Female youth and the protective effect of parental support. AIDS Behav. 2016;20:2203-2211.

10. Seelman KL. Transgender adults' access to college bathrooms and housing and the relationship to suicidality. J Homosex. 2016;10:1378-1399.

11. Hendricks ML, Testa RJ. A conceptual framework for clinical work with transgender and gender nonconforming clients: an adaptation of the minority stress model. Prof Psychol Res Pract. 2012;43:460-467.

12. Testa RJ, Habarth J, Peta J, et al. Development of the gender minority stress and resilience measure. Psychol Sex Orientat Gend Divers. 2015;2:65-77.

13. Herman J. Gendered restrooms and minority stress: the public regulation of gender and its impact on transgender people's lives. J Public Manag Soc Policy. 2013;19:65-80.

14. Rosenberg M. Society and the Adolescent Self-Image. Princeton, NJ: Princeton University Press, 1965.

15. Nicholson WD, Long BC. Self-esteem, social support, internalized homophobia, and coping strategies of HIV+ gay men. J Consult Clin Psychol. 1990;58:873.

16. Savin-Williams RC. Gay and lesbian adolescents. Marriage Fam Rev. 1990;14:197-216.
17. Logie $\mathrm{CH}$, Earnshaw V. Adapting and validating a scale to measure sexual stigma among lesbian, bisexual and queer women. PLoS One. 2015;10:e0116198.

18. Wagnild G, Young H. Development and psychometric. J Nurs Meas. 1993;1:165-178.

19. Losoi H, Turunen S, Wäljas M, et al. Psychometric properties of the Finnish version of the Resilience Scale and its short version. Psychol Commun Health. 2013;2:1-10.

20. Ahern NR, Kiehl EM, Lou Sole M, Byers J. A review of instruments measuring resilience. Issues Compr Pediatr Nurs. 2006;29:103-125.

21. Wagnild G. A review of the Resilience Scale. J Nurs Meas. 2009;17:105-113.

22. Edwards TC, Huebner CE, Connell FA, Patrick DL. Adolescent quality of life part I: conceptual and measurement model. J Adolesc. 2002;25:275-286.

23. Patrick DL, Edwards TC, Topolski TD. Adolescent quality of life. Part II: initial validation of a new instrument. J Adolesc. 2002;25:287-300.

24. Bjornson KF, Belza B, Kartin D, et al. Self-reported health status and quality of life in youth with cerebral palsy and typically developing youth. Arch Phys Med Rehab. 2008;89:121-127.

25. Patrick DL, Bell JF, Huang JY, et al. Bullying and quality of life in youths perceived as gay, lesbian, or bisexual in Washington State, 2010. Am J Public Health. 2013;103:1255-1261.

26. Braun V, Clarke V. Using thematic analysis in psychology. Qual Res Psychol. 2006;3:77-101

27. Riessman C. Narrative Methods for the Human Sciences. Los Angeles, CA: SAGE, 2008.

28. Stevens PE. Focus groups: collecting aggregate-level data to understand community health phenomena. Public Health Nurs. 1996;13:170-176.

29. Singh AA, Meng SE, Hansen AW. 'I am my own gender': resilience strategies of trans youth. J Couns Dev. 2014;92:208-218.

30. Porta CM, Gower AL, Mehus CJ, et al. "Kicked out": LGBTQ youths' bathroom experiences and preferences. J Adolesc. 2017;56:107-112.

Cite this article as: Weinhardt LS, Stevens $P$, Xie H, Wesp LM, John SA, Apchemengich I, Kioko D, Chavez-Korell S, Cochran KM, Watjen JM, Lambrou NH (2017) Transgender and gender nonconforming youths' public facilities use and psychological well-being: a mixed-method study, Transgender Health 2:1, 140-150, DOI: 10.1089/trgh.2017.0020.

$\begin{aligned} & \text { Abbreviations Used } \\ & \mathrm{DOE}=\text { U.S. Department of Education } \\ & \mathrm{DOJ}=\text { U.S. Department of Justice } \\ & \mathrm{GSA}=\text { gender and sexual alliance } \\ & \mathrm{PTSD}=\text { post-traumatic stress disorder } \\ & \mathrm{QoL}=\text { quality of life } \\ & \mathrm{RS}=\text { Resilience Scale } \\ & \mathrm{RSES}=\text { Rosenberg Self-Esteem Scale } \\ & \mathrm{SD}=\text { standard deviation } \\ & \mathrm{TGNC}=\text { transgender and gender nonconforming } \\ & \mathrm{YQOL}=\text { youth quality of life }\end{aligned}$

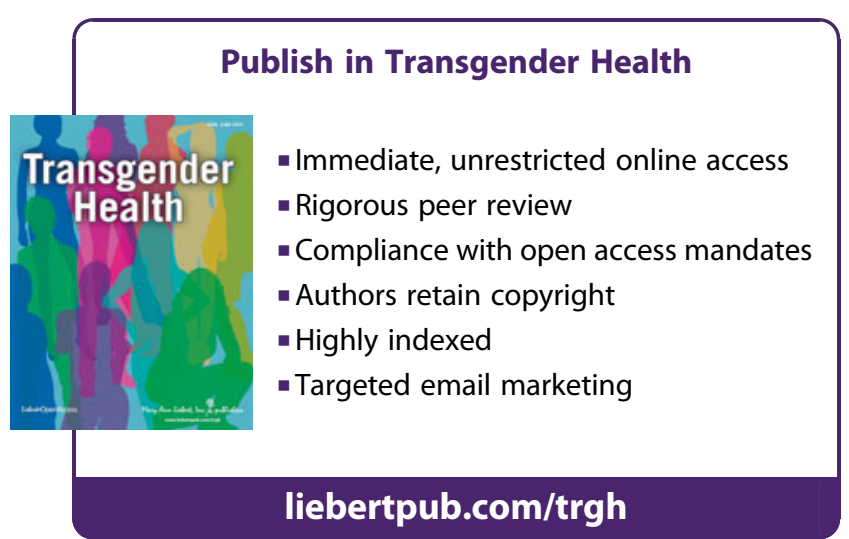

